Check for updates

Cite this: RSC Adv., 2017, 7, 31173

\title{
Colloidal synthesis and magnetic properties of anisotropic-shaped spinel $\mathrm{CuCr}_{2} \mathrm{Se}_{4}$ nanocrystals $\uparrow$
}

\author{
Chao Pang, (D) $\dot{t}^{\mathrm{ab}}$ Ruiqiang Yang, $\dot{\dagger}^{\mathrm{a}}$ Amit Singh, ${ }^{\mathrm{b}}$ Hanjiao Chen, ${ }^{\mathrm{c}}$ Michael K. Bowman, ${ }^{\mathrm{c}}$ \\ Ningzhong Bao, ${ }^{a}$ Liming Shen ${ }^{\star a}$ and Arunava Gupta ${ }^{\star b c}$
}

Anisotropic-shaped $\mathrm{CuCr}_{2} \mathrm{Se}_{4}$ nanocrystals have been synthesized by thermal decomposition and reaction of novel mixed metal-oleate complexes with selenium in a high-boiling point organic solvent, trioctylamine (TOA). The synthesized $\mathrm{CuCr}_{2} \mathrm{Se}_{4}$ nanocrystals exhibit close to triangular and hexagonal morphology, with an average size of $20 \mathrm{~nm}$. X-ray diffraction patterns and XPS spectral analysis confirm the formation of the pure spinel phase without any impurities. A possible reaction mechanism is suggested and formation pathways for the triangular and hexagonal shaped $\mathrm{CuCr}_{2} \mathrm{Se}_{4}$ nanocrystals are proposed. Magnetic studies indicate that the anisotropic-shaped $\mathrm{CuCr}_{2} \mathrm{Se}_{4}$ nanocrystals are superparamagnetic near room temperature but exhibit ferromagnetic behavior at lower temperatures, with magnetization values of 31 and $43 \mathrm{emu} \mathrm{g}^{-1}$ at 300 and $5 \mathrm{~K}$, respectively.

Received 25th March 2017 Accepted 11th June 2017

DOI: $10.1039 / c 7 r a 03473 c$

rsc.li/rsc-advances chromium and the limited known nonvolatile chalcogen precursors for selective synthesis of the spinel phase, the exploration of novel routes for preparing $\mathrm{Cr}$-based chalcospinel nanomaterials with desired morphology remains a challenge. ${ }^{13}$

An important class of magnetic chalcospinels, $\mathrm{CuCr}_{2} \mathrm{~S}_{4}$, $\mathrm{CuCr}_{2} \mathrm{Se}_{4}$, and $\mathrm{CuCr}_{2} \mathrm{Te}_{4}$, are ferromagnetic metals with Curie temperatures $\left(T_{\mathrm{c}}\right)$ of 377,430 , and $360 \mathrm{~K}$, respectively, and are also metallic. Because of their high Curie temperature, these materials are potentially attractive candidates for spin-based electronics. $^{14}$ They have also been reported to exhibit a pronounced room temperature magneto-optical Kerr effect. ${ }^{15}$ Moreover, based on band structure calculations, we predicted the exciting possibility of inducing half-metallicity in some of the cation-substituted $\mathrm{Cu}, \mathrm{Cd}$ chalcospinels $\left(\mathrm{Cu}_{x} \mathrm{Cd}_{1-x} \mathrm{Cr}_{2^{-}}\right.$ $\mathrm{S}(\mathrm{Se})_{4}$ ), which makes them promising candidates for spintronic applications. ${ }^{16,17}$ Because of these unique characteristics, there have been several efforts in developing synthetic routes for obtaining $\mathrm{CuCr}_{2} \mathrm{~S}(\mathrm{Se}, \mathrm{Te})_{4}$ nanocrystals. ${ }^{18,19}$ In previous studies, we reported on the colloidal syntheses of various ternary $\left(\mathrm{CuCr}_{2} \mathrm{~S}(\mathrm{Se}, \mathrm{Te})_{4}, \mathrm{CdCr}_{2} \mathrm{~S}_{4}, \mathrm{CuSbS}_{2}\right.$, and $\left.\mathrm{CuInS}_{2}\right)$ and quaternary $\left(\mathrm{Culn}_{x} \mathrm{Ga}_{1-x} \mathrm{~S}(\mathrm{Se})_{2}\right.$ and $\left.\mathrm{Cu}_{2} \mathrm{ZnSnS}_{4}\right)$ chalcogenide nanocrystals with tunable size and shape control. ${ }^{18-23}$ However, for the magnetic Cr-based chalcospinels, the morphologies of the kinetically favorable nanocrystals are mostly spherical or cubic, with the exposed surfaces not being specific crystal planes that can significantly influence their physicochemical and magnetic properties. The preparation of magnetic Cr-based chalcospinel nanomaterials with anisotropic shapes thus remains rather limited.

One of the more efficient routes for the synthesis of anisotropic-shaped magnetic nanocrystals involves thermal decomposition of organometallic precursors, such as metal

\footnotetext{
${ }^{a}$ State Key Laboratory of Materials-Oriented Chemical Engineering, Nanjing Tech University, Nanjing, Jiangsu 210009, P. R. China. E-mail: lshen@njtech.edu.cn

${ }^{b}$ Center for Materials for Information Technology (MINT), The University of Alabama, Tuscaloosa, AL 35487, USA. E-mail: agupta@mint.ua.edu

'Department of Chemistry, The University of Alabama, Tuscaloosa, AL 35487, USA $\dagger$ Electronic supplementary information (ESI) available. See DOI: $10.1039 / \mathrm{c} 7 \mathrm{ra03473 \textrm {c }}$

\$ These authors contributed equally to this work.
}

decomposition of organometallic precursors, such as metal 
acetylacetonates, metal carbonyls, etc., in high-boiling point solvents by hot-injection in the presence of suitable surfactants. This procedure has been utilized for the synthesis of a variety of magnetic metals, magnetic oxides, and some non-chromiumbased chalcogenide nanoparticles with good crystallinity and anisotropic shapes. ${ }^{\mathbf{2 4 , 2 5}}$ Particularly noteworthy is the recent development of inexpensive, environmental-friendly metaloleate complexes, which have been shown to be promising precursors for ultra-large-scale thermolysis synthesis of magnetic nanocrystals. ${ }^{26}$ Herein, we report on a simple, highly efficient synthesis route for preparing single-phase anisotropicshaped $\mathrm{CuCr}_{2} \mathrm{Se}_{4}$ nanocrystals. The process involves the thermal decomposition and reaction of novel mixed metaloleate complexes with selenium in a high-boiling point organic solvent trioctylamine (TOA). We have further investigated in detail the structural and magnetic properties of the assynthesized triangular and hexagonal $\mathrm{CuCr}_{2} \mathrm{Se}_{4}$ nanocrystals.

\section{Experimental}

\section{Materials}

Copper(II) chloride dihydrate $\left(\mathrm{CuCl}_{2} \cdot 2 \mathrm{H}_{2} \mathrm{O}\right.$, 99.99\%), sodium oleate $\left(\mathrm{C}_{18} \mathrm{H}_{33} \mathrm{O}_{2} \mathrm{Na}\right.$, 99.99\%), elemental selenium (Se, 99.99\%), and trioctylamine $\left(\mathrm{C}_{24} \mathrm{H}_{51} \mathrm{~N}, 90 \%\right)$ were purchased from Aladdin Chemical and used without further purification. Chromium(III) chloride hexahydrate $\left(\mathrm{CrCl}_{3} \cdot 6 \mathrm{H}_{2} \mathrm{O}, 99.99 \%\right)$ was obtained from Xi Long Chemical. Absolute ethanol, deionized water, and hexane were supplied by Aladdin Chemical as commercially available reagents and used without further purification.

\section{Preparation of metal-oleate complexes $\mathrm{Cu}\left(\mathrm{C}_{18} \mathrm{H}_{33} \mathrm{O}_{2}\right)_{2}$ and $\mathrm{Cr}\left(\mathrm{C}_{18} \mathrm{H}_{33} \mathrm{O}_{2}\right)_{3}$}

Synthesis of the metal-oleate $\mathrm{Cu}\left(\mathrm{C}_{18} \mathrm{H}_{33} \mathrm{O}_{2}\right)_{2}$ and $\mathrm{Cr}\left(\mathrm{C}_{18} \mathrm{H}_{33} \mathrm{O}_{2}\right)_{3}$ complexes followed the procedure reported by Park et al. ${ }^{26}$ by reaction of sodium oleate and $\mathrm{Cu}^{2+}$ or $\mathrm{Cr}^{3+}$ chlorides. In a typical synthesis, $5 \mathrm{mmol}$ of $\mathrm{CuCl}_{2} \cdot 2 \mathrm{H}_{2} \mathrm{O}\left(5 \mathrm{mmol}\right.$ of $\left.\mathrm{CrCl}_{3} \cdot 6 \mathrm{H}_{2} \mathrm{O}\right)$, $10 \mathrm{mmol}(15 \mathrm{mmol})$ of sodium oleate $\left(\mathrm{C}_{18} \mathrm{H}_{33} \mathrm{O}_{2} \mathrm{Na}\right), 50 \mathrm{~mL}$ of $\mathrm{H}_{2} \mathrm{O}, 50 \mathrm{~mL}$ of ethanol, and $80 \mathrm{~mL}$ of hexane were mixed and refluxed at $60{ }^{\circ} \mathrm{C}$ for $3 \mathrm{~h}$. The metal-oleate $\mathrm{Cu}\left(\mathrm{C}_{18} \mathrm{H}_{33} \mathrm{O}_{2}\right)_{2}$ and $\mathrm{Cr}\left(\mathrm{C}_{18} \mathrm{H}_{33} \mathrm{O}_{2}\right)_{3}$ complexes were obtained by separation of the water phase and subsequent evaporation of the residual ethanol and hexane at $70{ }^{\circ} \mathrm{C}$ and water at $110^{\circ} \mathrm{C}$.

\section{Synthesis of anisotropic-shaped $\mathrm{CuCr}_{2} \mathrm{Se}_{4}$ nanocrystals}

All the experiments were carried out in a fume hood using standard Schlenk techniques, and any excess elemental Se was disposed of using safe laboratory techniques. In a typical synthesis of triangular and hexagonal shaped $\mathrm{CuCr}_{2} \mathrm{Se}_{4}$ nanocrystals, $2 \mathrm{mmol}$ Se powder was dissolved in $15 \mathrm{~mL}$ of TOA at $320{ }^{\circ} \mathrm{C}$ and maintained at this temperature for $1 \mathrm{~h}$ under $\mathrm{N}_{2}$ before cooling down to room temperature. The mixture was subsequently heated to $160-165{ }^{\circ} \mathrm{C}$ under vacuum and then to $300{ }^{\circ} \mathrm{C}$ under $\mathrm{N}_{2}$. Separately, $0.25 \mathrm{mmol}$ of $\mathrm{Cu}\left(\mathrm{C}_{18} \mathrm{H}_{33} \mathrm{O}_{2}\right)_{2}$ and $0.5 \mathrm{mmol}$ of $\mathrm{Cr}\left(\mathrm{C}_{18} \mathrm{H}_{33} \mathrm{O}_{2}\right)_{3}$ complexes, along with $2.5 \mathrm{~mL}$ of TOA, were heated to $175{ }^{\circ} \mathrm{C}$ and magnetically stirred under flowing $\mathrm{N}_{2}$ for $1 \mathrm{~h}$. At $300{ }^{\circ} \mathrm{C}, 2.5 \mathrm{~mL}$ of hot metal-oleate complexes and TOA mixture were rapidly injected into the Se solution under nitrogen atmosphere and the reaction mixture was maintained at this temperature for $30 \mathrm{~min}$ while being continually stirred, during which a brown-black solution was formed. After the mixture cooled down to room temperature, a mixture of hexane and ethanol (1:3) was added to the solution. The resulting black precipitate was collected via centrifugation (6500 rpm, $5 \mathrm{~min}$ ) and washed three times before drying.

\section{Characterization}

XRD patterns were recorded on a Rigaku-Smart Lab Advance system equipped with $\mathrm{Cu} K \alpha$ radiation source operated as a rotating anode at $40 \mathrm{kV}$ and $100 \mathrm{~mA}$. Transmission electron microscopy (TEM) analysis was performed using a JEOL JEM2010 UHR, $200 \mathrm{kV}$ transmission electron microscope equipped with a CCD camera. TEM image non-linear processing was carried out using Gatan digital micrograph version 3.9. Scanning electron microscopy (SEM) analysis was performed using a Hitachi S-4800 FESEM equipped with EDX detector. X-ray photoelectron spectroscopy (XPS) analysis was carried out on a Thermo Scientific K-Alpha spectrometer. Magnetic measurements were performed using a Quantum Design Dynacool Physical Properties Measurement System (PPMS) equipped with Vibrating Sample Magnetometer (VSM). Continuous wave (CW) EPR spectra were recorded in the temperature range of 260-370 K on a Bruker ELEXYS E540 X-band spectrometer equipped with an ER 4102 ST resonator (Bruker-Biospin, Billerica, MA) and an ER 4111VT variable temperature unit (Bruker). CW simulations data processing was performed using MATLAB EasySpin program.

\section{Results and discussion}

For the synthesis of anisotropic-shaped $\mathrm{CuCr}_{2} \mathrm{Se}_{4}$ nanostructures, we used TOA as a reducing agent for the reduction of selenium. Based on nuclear magnetic resonance spectra and mass spectra (NMR and mass data, ESI), we propose a mechanism for the reduction process. The reaction primarily leads to the formation of TOASe and some tri-octylamine- $N$-selenide. Besides, we determined that reaction temperatures below $300{ }^{\circ} \mathrm{C}$ predominantly favors the formation of the nonmagnetic phase $\mathrm{CuCrSe}_{2}$, as confirmed by X-ray diffraction (Fig. S1, ESI $\dagger$ ). Based on X-ray diffraction studies, it is apparent that the reaction initially leads to the formation of $\mathrm{CuCrSe}_{2}$ and subsequently to $\mathrm{CuCr}_{2} \mathrm{Se}_{4}$ (Fig. S2, ESI $\dagger$ ). Referring to the reaction mechanism suggested by Steckel et al. ${ }^{27}$ we propose a possible mechanism for the formation of $\mathrm{CuCr}_{2} \mathrm{Se}_{4}$ in Scheme 1 shown below.

$$
\begin{gathered}
\left(\mathrm{R}_{\mathrm{a}} \mathrm{COO}\right)_{2}-\mathrm{Cu}+2\left(\mathrm{R}_{\mathrm{a}} \mathrm{COO}\right)_{3}-\mathrm{Cr}+4 \mathrm{R}_{\mathrm{b}} \mathrm{SeH} \rightarrow \\
\mathbf{R}_{\mathrm{b}} \mathrm{Se}-\mathrm{Cu}-\mathrm{Cr}-\left(\mathrm{OOCR}_{\mathrm{a}}\right)\left(\mathrm{SeR}_{\mathrm{b}}\right)+\mathrm{Cr}-\left(\mathrm{OOCR}_{\mathrm{a}}\right)\left(\mathrm{SeR}_{\mathrm{b}}\right)_{2}+6 \mathrm{R}_{\mathrm{a}} \mathrm{COOH} \rightarrow \\
\mathrm{CuCr}_{2} \mathrm{Se}_{4}+4 \mathrm{R}_{\mathrm{a}} \mathrm{COOH}+4 \mathrm{R}_{\mathrm{b}} \mathrm{OOCR}_{\mathrm{a}} \\
\mathrm{R}_{\mathrm{a}}=\mathrm{CH}_{3}\left(\mathrm{CH}_{2}\right)_{7} \mathrm{CH}=\mathrm{CH}\left(\mathrm{CH}_{2}\right)_{7} \mathrm{CH}_{3} ; \mathrm{R}_{\mathrm{b}} \mathrm{H}=\mathrm{TOA}
\end{gathered}
$$

Scheme 1 Proposed reaction mechanism for the formation of $\mathrm{CuCr}_{2} \mathrm{Se}_{4}$ nanocrystals. 

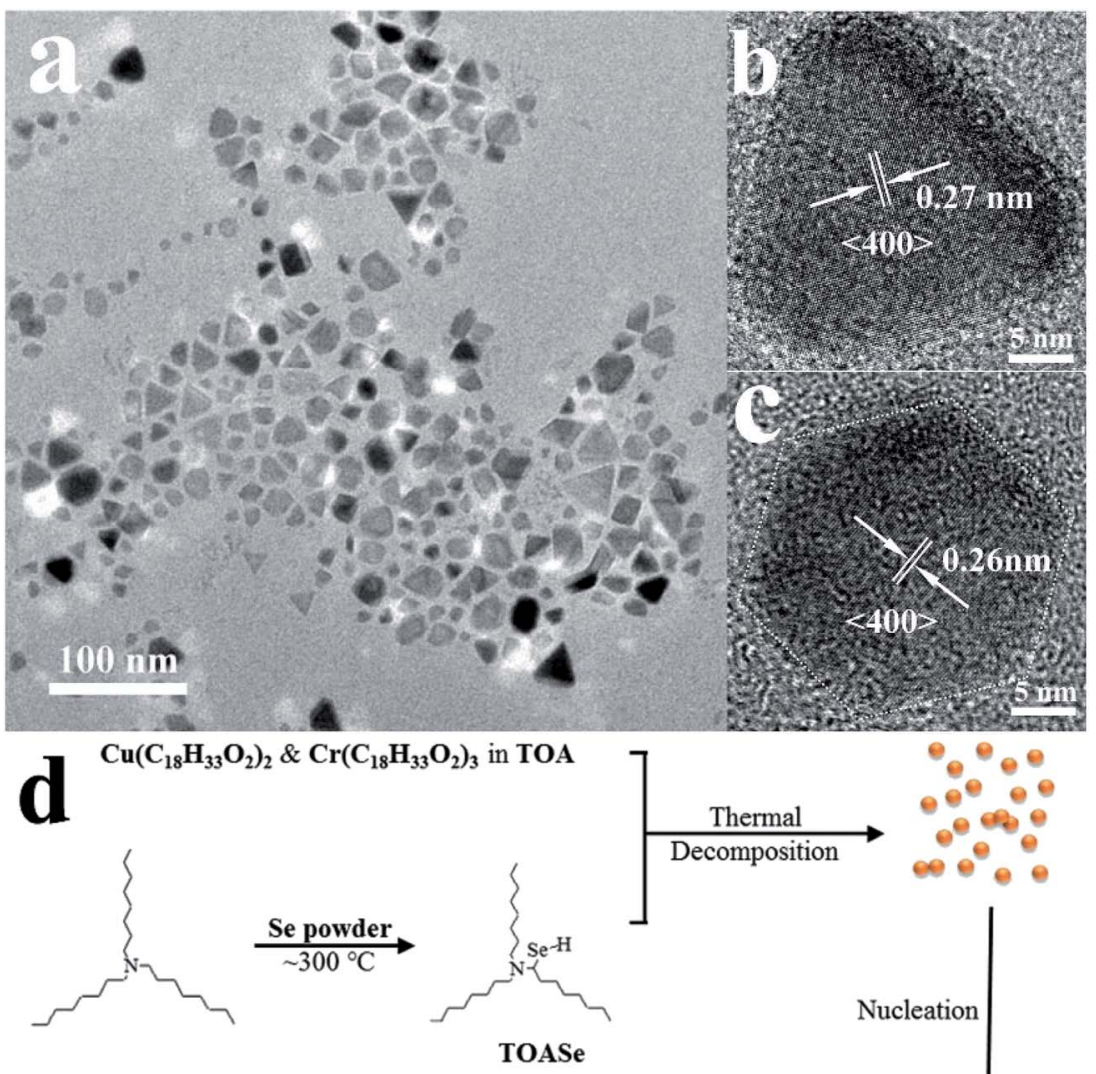

Thermal
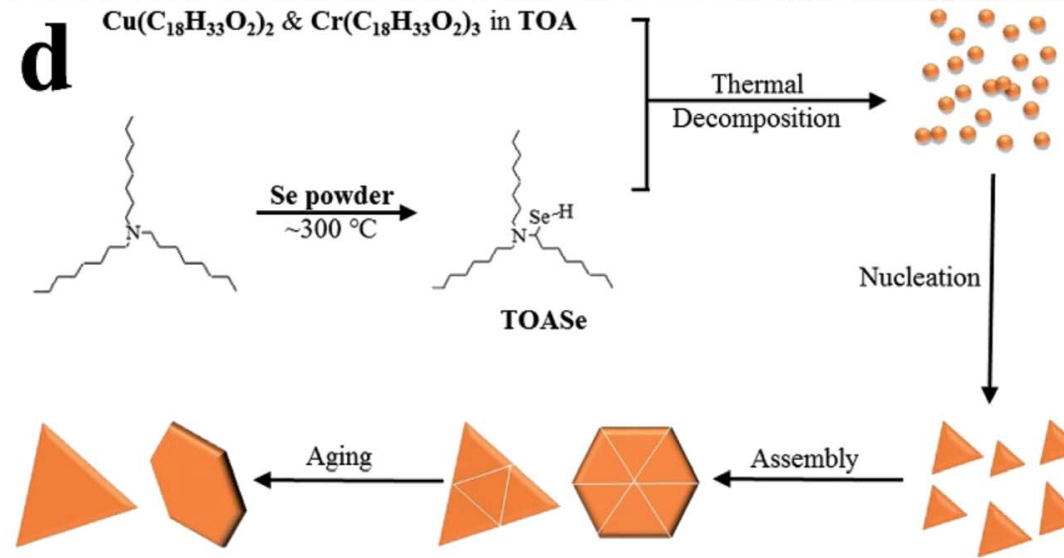

Fig. 1 (a) TEM and (b and c) HRTEM images of the $\mathrm{CuCr}_{2} \mathrm{Se}_{4}$ nanocrystals. (d) Schematic illustration of the possible formation pathway of the $\mathrm{CuCr}_{2} \mathrm{Se}_{4}$ nanocrystals.

The morphology and structure of the $\mathrm{CuCr}_{2} \mathrm{Se}_{4}$ nanocrystals have been investigated by transmission electron microscopy (TEM). As shown in Fig. 1, the synthesized $\mathrm{CuCr}_{2} \mathrm{Se}_{4}$ nanocrystals exhibit a mixture of close to triangular and hexagonal morphology, with an average size of $20 \mathrm{~nm}$. Fig. 1b and c show high-resolution TEM (HRTEM) images of the two distinct shape nanocrystals that exhibit lattice fringes. Lattice spacing's of $d=$ $0.27 \mathrm{~nm}$ for triangular morphology and $0.26 \mathrm{~nm}$ for hexagonal morphology are observed, corresponding to the (400) lattice planes of the face-central cubic chalcospinel phase. Based on thorough analysis of our results and suggested formation pathways reported in the literature, ${ }^{28}$ we propose a likely formation pathway for the triangular and hexagonal $\mathrm{CuCr}_{2} \mathrm{Se}_{4}$ nanocrystals, as illustrated in Fig. 1d. In the reaction, metaloleate complexes have lower decomposition temperatures $\left(\sim 300{ }^{\circ} \mathrm{C}\right)$ than previously utilized metal-acetylacetonate precursors $\left(\sim 350{ }^{\circ} \mathrm{C}\right)$. Our earlier results have shown that the metal-acetylacetonate precursors favor the formation of cubic morphology of $\mathrm{CuCr}_{2} \mathrm{Se}_{4}$ nanocrystals. ${ }^{18}$ Due to the slower decomposition rate at the lower temperature than using metalacetylacetonate precursors reacted in a solution of octadecene and oleylamine, the nucleation of $\mathrm{CuCr}_{2} \mathrm{Se}_{4}$ nanocrystals using the oleate precursors will be slower resulting in a lower concentration of monomers. Besides, the role of solvent as stabilizer and surfactant in the colloidal synthesis of

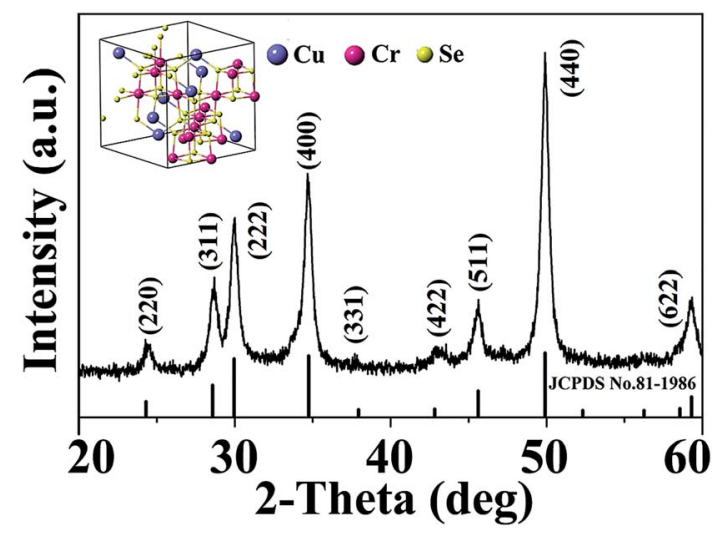

Fig. 2 XRD pattern of synthesized $\mathrm{CuCr}_{2} \mathrm{Se}_{4}$ nanocrystals. Inset shows the crystal structure of $\mathrm{CuCr}_{2} \mathrm{Se}_{4}$ and the standard XRD stick pattern of bulk $\mathrm{CuCr}_{2} \mathrm{Se}_{4}$ (JCPDS no. 81-1986) is also shown. 

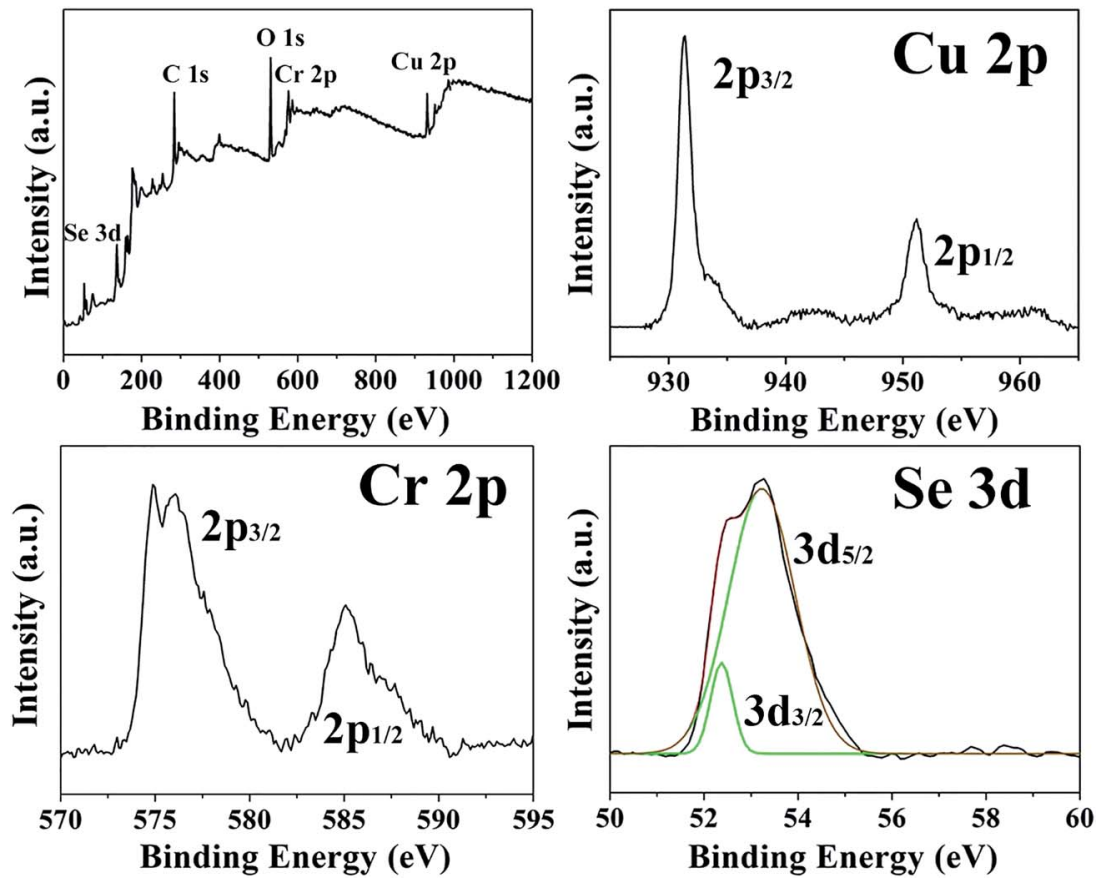

Fig. 3 XPS survey spectrum of the $\mathrm{CuCr}_{2} \mathrm{Se}_{4}$ nanocrystals, and high resolution XPS spectra of $\mathrm{Cu} 2 \mathrm{p}, \mathrm{Cr} 2 \mathrm{p}$, and $\mathrm{Se}_{3} \mathrm{~d}$ of the CuCr $\mathrm{Se}_{4}$ nanocrystals.

nanocrystals will also have a significant influence. These factors kinetically favor formation of the thermodynamically unstable triangular and hexagonal morphology. However, limited by the relatively higher aging temperature and the imperfection of the assembly, some nanocrystals deviating from triangular and hexagonal shapes are also formed.

X-ray diffraction (XRD) measurements confirm the phase purity of the as-synthesized $\mathrm{CuCr}_{2} \mathrm{Se}_{4}$ nanocrystals, as shown in Fig. 2, and the diffraction pattern matches very well with the face-centered cubic spinel structure with $F d \overline{3} m$ space group (shown in Fig. 2 inset). The major diffraction peaks are indexed as (220), (311), (222), (400), (331), (422), (511), (440), and (622) planes of cubic $\mathrm{CuCr}_{2} \mathrm{Se}_{4}$ phase (JCPDS no. 81-1986). Based on the peak positions, the lattice parameter is calculated to be $10.17 \AA$ for the $\mathrm{CuCr}_{2} \mathrm{Se}_{4}$ nanocrystals, which is close to the value reported for bulk $\mathrm{CuCr}_{2} \mathrm{Se}_{4}(10.337 \AA) .{ }^{11}$ Additionally, we have used energy dispersive X-ray analysis (EDX) to determine the elemental ratio of the $\mathrm{CuCr}_{2} \mathrm{Se}_{4}$ nanocrystals, which shows that the $\mathrm{Cu}: \mathrm{Cr}$ : Se concentration ratio is close to the expected value of $1: 2: 4$ (Fig. S3, ESI†).

X-ray photoelectron spectroscopy (XPS) studies have been carried out to investigate the chemical states of the ions in the $\mathrm{CuCr}_{2} \mathrm{Se}_{4}$ nanocrystals. A survey spectrum of the synthesized nanocrystals helps identify the presence of $\mathrm{Cu}, \mathrm{Cr}, \mathrm{Se}, \mathrm{O}$ and $\mathrm{C}$, and high-resolution spectra of $\mathrm{Cu} 2 \mathrm{p}, \mathrm{Cr} 2 \mathrm{p}$, and Se $3 \mathrm{~d}$ are measured to determine the oxidation states of the constituent elements (Fig. 3). In the $\mathrm{Cu} 2 \mathrm{p}$ spectrum, peaks at 931.4 and $951.2 \mathrm{eV}$ are ascribed to $\mathrm{Cu} 2 \mathrm{p}_{3 / 2}$ and $\mathrm{Cu} 2 \mathrm{p}_{1 / 2}$, which can be assigned to $\mathrm{Cu}$ (II) with peak splitting of $19.8 \mathrm{eV}^{29}$ The $\mathrm{Cr} 2 \mathrm{p}$ spectrum exhibits a spin-orbit separation of $9.7 \mathrm{eV}$ between the Cr $2 \mathrm{p}_{3 / 2}$ and $\mathrm{Cr} 2 \mathrm{p}_{1 / 2}$ states, indicative of $\mathrm{Cr}(\mathrm{III}){ }^{30}$ The $\mathrm{Cr} 2 \mathrm{p}_{3 / 2}$ states are split into two peaks at 574.9 and $576.0 \mathrm{eV}$. The peak
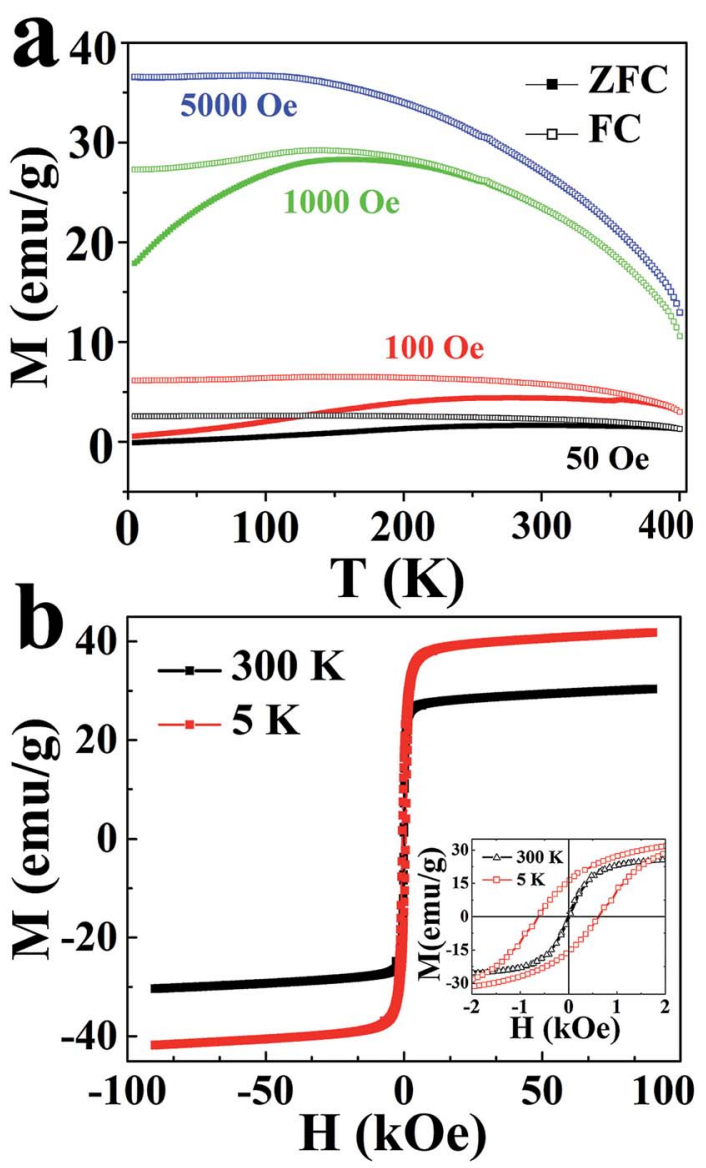

Fig. 4 (a) Zero-field-cooled (ZFC) and field-cooled (FC) magnetization $(M)$ versus temperature $(T)$ of the $\mathrm{CuCr}_{2} \mathrm{Se}_{4}$ nanocrystals measured at different magnetic fields. (b) Magnetization as a function of field measured at 5 and $300 \mathrm{~K}$. The inset in (b) displays an enlarged portion of the hysteresis loops measured at 5 and $300 \mathrm{~K}$. 
separation with the binding energy difference $\Delta E$ of about $1 \mathrm{eV}$ is typical of the $3 \mathrm{~d}$ elements. Such a value of $\Delta E$ has been reported for a number of chalcogenide spinels. ${ }^{31}$ The peaks identified at 52.4 and $53.2 \mathrm{eV}$ in the high-resolution spectrum of Se are generally attributed to $\mathrm{Se} 3 \mathrm{~d}_{3 / 2}$ and Se $3 \mathrm{~d}_{5 / 2}$, respectively. ${ }^{32}$ These results further confirm that the as-prepared nanocrystals are primarily $\mathrm{CuCr}_{2} \mathrm{Se}_{4}$.

The magnetic properties of the phase-pure mixture of triangular and hexagonal-shaped $\mathrm{CuCr}_{2} \mathrm{Se}_{4}$ nanocrystals have been measured using a Quantum Design Dynacool Physical Properties Measurement System (PPMS) equipped with a Vibrating Sample Magnetometer (VSM). A series of zero-fieldcooled (ZFC) and field-cooled (FC) scans are shown in Fig. 4a, in which the magnetization is plotted as a function of temperature for several different applied magnetic fields. The ZFC and FC curves measured at magnetic fields of 50, 100 and 1000 Oe are distinct at lower temperatures but merge together at higher temperatures, which is different from the curves measured at a higher magnetic field (5000 Oe). This is a typical characteristic of superparamagnetism resulting from the very small crystalline size of the nanocrystals. ${ }^{33}$ The Curie temperature is much higher than room temperature, with the blocking temperature obtained from the low-field (50 Oe) ZFC-FC measurement being $\sim 390 \mathrm{~K}$. This is higher than the blocking temperature reported for $25 \mathrm{~nm}$ cubic $\mathrm{CuCr}_{2} \mathrm{Se}_{4}$ nanocrystals $\left(T_{\mathrm{b}}=250 \mathrm{~K}, 50 \mathrm{Oe}\right) \cdot{ }^{18} \mathrm{It}$ is known that the blocking temperature $T_{\mathrm{b}}$ depends on interparticle interactions, ${ }^{\mathbf{3 4}, 35}$ which will vary with morphology. The $T_{\mathrm{b}}$ behavior can be modeled for single-domain particles by the Stoner-Wohlfarth equation $T_{\mathrm{b}}=K V \sin ^{2} \theta / k_{\mathrm{B}} \ln \left(\tau_{\mathrm{m}} / \tau_{0}\right)$, where $K$ is the nanoparticle's magnetic anisotropy energy density; $\theta$ is the angle between the net nanoparticle moment and the magnetic easy axis; $V$ is the nanoparticle volume; $k_{\mathrm{B}}$ is the Boltzmann constant; $T_{\mathrm{b}}$ is the blocking temperature; and $\ln \left(\tau_{\mathrm{m}} /\right.$ $\tau_{0}$ ) is invariable for dc magnetic measurements, when the measurement time is kept constant. ${ }^{36}$ Thus, the larger total anisotropy energy will lead to a higher blocking temperature.

Fig. $4 \mathrm{~b}$ shows plots of the magnetization as a function of applied magnetic field at 5 and $300 \mathrm{~K}$, respectively. As indicated, the triangular and hexagonal $\mathrm{CuCr}_{2} \mathrm{Se}_{4}$ nanocrystals exhibit superparamagnetic behavior (no hysteresis and zero remanence) at room temperature but exhibit ferromagnetic behavior with a coercivity value of $\sim 1 \mathrm{kOe}$ at $5 \mathrm{~K}$. The low temperature saturation magnetization value is $\sim 43 \mathrm{emu}^{-1}$ at a field of 90 kOe, which is similar to the value of $25 \mathrm{~nm}$ cubic $\mathrm{CuCr}_{2} \mathrm{Se}_{4}$ nanocrystals reported previously. ${ }^{18}$ The superparamagnetic nanocrystals at $300 \mathrm{~K}$ exhibit a saturation magnetization value of $\sim 31 \mathrm{emu} \mathrm{g}^{-1}$. Nanocrystals with narrow size dispersion show the peak and bifurcation point at the same temperature in $\mathrm{FC}-$ ZFC measurements, corresponding to the superparamagnetic blocking temperature. However, for our nanocrystals the peak and bifurcation point occur at different temperatures, suggesting a broad size distribution as confirmed from TEM images in Fig. 1a. In this case, we can refer the peak to an ensemble average blocking temperature and the bifurcation point as the largest blocking temperature. Thus, the synthesized triangular and hexagonal $\mathrm{CuCr}_{2} \mathrm{Se}_{4}$ nanocrystals exhibit superparamagnetic behavior at $300 \mathrm{~K}$, which is below the largest blocking temperature of $390 \mathrm{~K}$.

To further investigate the magnetic properties of anisotropicshaped $\mathrm{CuCr}_{2} \mathrm{Se}_{4}$ nanocrystals, electron paramagnetic resonance (EPR) spectroscopy has been used to detect the coupling interactions. The EPR signal is produced by localized 3d electrons of
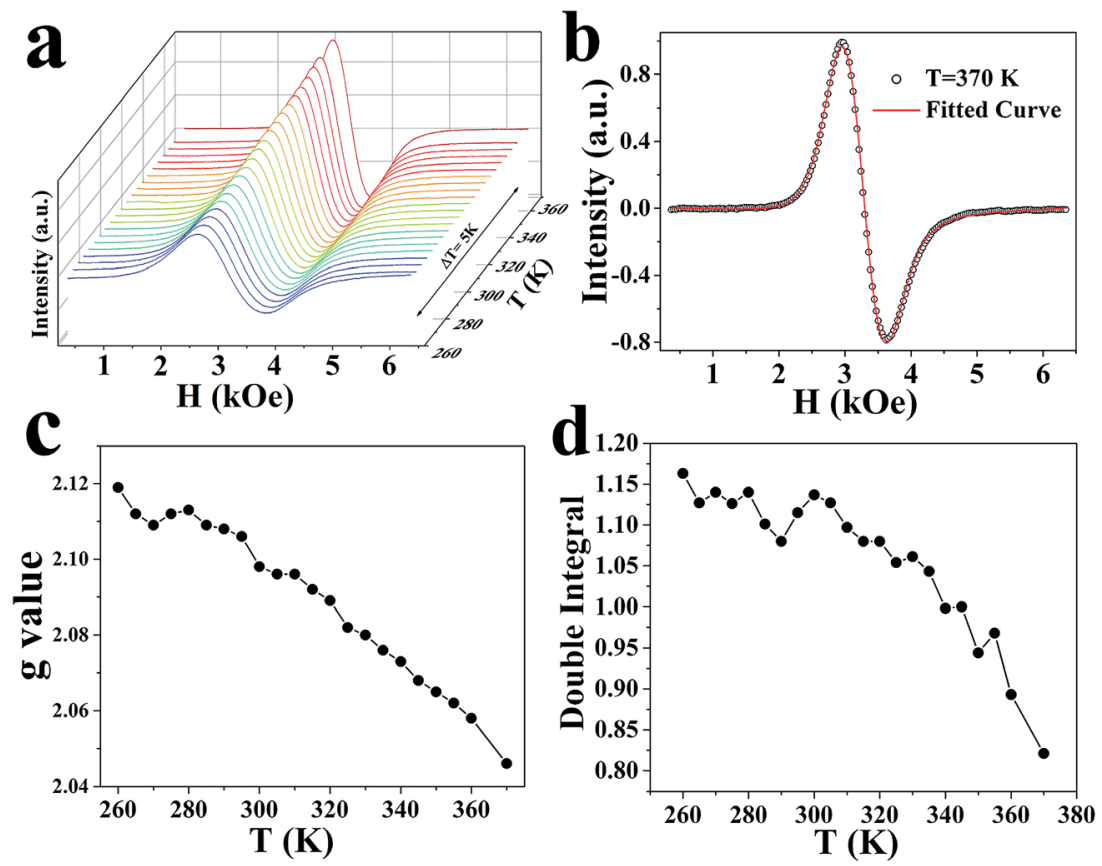

Fig. 5 (a) The differential EPR spectra from 260 to $370 \mathrm{~K}$ with steps of $5 \mathrm{~K}$. (b) EPR spectrum at $370 \mathrm{~K}$ fitted by a convolution of Gaussian and Lorentzian line shapes. (c) The $g$ values as a function of temperature. (d) Double integral of CW EPR spectra showing the spin susceptibility for the anisotropic-shaped $\mathrm{CuCr}_{2} \mathrm{Se}_{4}$ nanocrystals. 
$\mathrm{Cr}^{3+}$ ions. Fig. 5a shows the EPR spectra from 260 to $370 \mathrm{~K}$ with steps of $5 \mathrm{~K}$, which is below the magnetic transition temperature $\left(T_{\mathrm{c}}\right)$. The EPR first-derivative spectra become stronger and sharper at temperatures below $T_{\mathrm{c}}$ and can be fitted well by a convolution of Lorentzian and Gaussian line shapes (detailed fitting parameters shown in Fig. S4, ESI. $\dagger$ ). Fig. 5b shows the spectrum data and fitted curves at $370 \mathrm{~K}$. The extracted $g$ values are close to 2 , and increase as the temperature decreases, as shown in Fig. 5c. Fig. 5d shows the double integral of the CW EPR spectra, which gives the spin susceptibility for the anisotropic $\mathrm{CuCr}_{2} \mathrm{Se}_{4}$ nanocrystals. These behaviors suggest that the ferromagnetism of the sample adds an internal magnetic field to the applied field. Thus, a weaker applied field is required to achieve resonance at the lower temperatures and the apparent $g$ values are larger at lower temperatures, similar to results reported for bulk $\mathrm{CuCr}_{2} \mathrm{Se}_{4} \cdot{ }^{37}$ This may be due to the random orientation distribution of the nanocrystals present during measurement. The magnetic anisotropy in this system is thus dominated by the intrinsic lattice magnetocrystalline anisotropy, with only a minor shape anisotropy contribution. A detailed investigation of the influence of surface spins may be necessary and is underway.

\section{Conclusions}

In summary, we have developed a simple and highly efficient synthesis route for preparation of single-phase anisotropicshaped $\mathrm{CuCr}_{2} \mathrm{Se}_{4}$ nanocrystals. The process involves the thermal decomposition and reaction of novel mixed metaloleate complexes with selenium in a high-boiling point organic solvent trioctylamine. We have investigated and proposed a possible reaction mechanism and formation pathway for the triangular and hexagonal $\mathrm{CuCr}_{2} \mathrm{Se}_{4}$ nanocrystals. Furthermore, we studied the magnetic properties of anisotropic-shaped $\mathrm{CuCr}_{2} \mathrm{Se}_{4}$ nanocrystals. We believe the process can be extended to the synthesis and studies of other anisotropicshaped magnetic chromium-based chalcogenide nanocrystals.

\section{Acknowledgements}

This research was supported by the National Science Foundation of U.S under Grant No. CHE-1508259, the Natural Science Foundation of China (No. 51425202, No. 51202110), the Natural Science Foundation of Jiangsu Province (BK20160093), and the Project Funded by the Top-notch Academic Programs Project of Jiangsu Higher Education Institutions (TAPP). We are grateful to Ziyou Zhou for help with the TEM analysis. As a joint Ph.D. student, Chao Pang was also partially supported by the China Scholarship Council.

\section{Notes and references}

1 R. F. Ziolo, E. P. Giannelis, B. A. Weinstein, M. P. O'Horo, B. N. Ganguly, V. Mehrotra, M. W. Russel and D. R. Huffman, Science, 1992, 257, 219.

2 S. H. Sun, C. B. Murray, D. Weller, L. Folks and A. Moser, Science, 2000, 287, 1989.
3 A. M. Whyte, Y. Shuku, G. S. Nichol, M. M. Matsushita, K. Awaga and N. Robertson, J. Mater. Chem., 2012, 22, 17967.

4 W. Y. Zhao, Z. Y. Liu, P. Wei, Q. J. Zhang, W. T. Zhu, X. L. Su, X. F. Tang, J. H. Yang, Y. Liu, J. Shi, Y. M. Chao, S. Q. Lin and Y. Z. Pei, Nat. Nanotechnol., 2017, 12, 55.

5 L. He, M. Janner, Q. P. Lu, M. S. Wang, H. Ma and Y. D. Yin, Adv. Mater., 2015, 27, 86.

6 M. Planells, L. X. Reynolds, U. Bansode, S. Chhatre, S. Ogale, N. Robertson and S. A. Haque, Phys. Chem. Chem. Phys., 2013, 15, 7679.

7 F. Zhao, M. Rutherford, S. Y. Grisham and X. G. Peng, J. Am. Chem. Soc., 2009, 131, 5350.

8 F. Liu, J. H. Zhu, W. L. Yang, Y. H. Dong, Y. L. Hou, C. Z. Zhang, H. Yin and S. H. Sun, Angew. Chem., Int. Ed., 2014, 53, 2176.

9 J. Hemberger, P. Lunkenheimer, R. Fichtl, H.-A. Krug von Nidda, V. Tsurkan and A. Loidl, Nature, 2005, 434, 364.

10 M. Muroi, R. Street and P. G. McCormick, Phys. Rev. B: Condens. Matter Mater. Phys., 2001, 63, 052412.

11 M. Esters, A. Liebig, J. J. Ditto, M. Falmbigl, M. Albrecht and D. C. Johnson, J. Alloys Compd., 2016, 671, 220.

12 I. Efthimiopoulos, Z. T. Y. Liu, S. V. Khare, P. Sarin, V. Tsurkan, A. Loidl, D. Popov and Y. Wang, Phys. Rev. B, 2016, 93, 174103.

13 V. A. Fedorov, Y. A. Kesler and E. G. Zhukov, Inorg. Mater., 2003, 39, S68.

14 A. P. Ramirez, R. J. Cava and J. Krajewski, Nature, 1997, 386, 156.

15 V. N. Antonov, V. P. Antropov, B. N. Harmon, A. N. Yaresko and A. Y. Perlov, Phys. Rev. B: Condens. Matter Mater. Phys., 1999, 59, 14552.

16 Y.-H. A. Wang, A. Gupta, M. Chshiev and W. H. Butler, Appl. Phys. Lett., 2008, 92, 062507.

17 Y.-H. A. Wang, A. Gupta, M. Chshiev and W. H. Butler, Appl. Phys. Lett., 2009, 94, 062515.

18 Y.-H. A. Wang, N. Z. Bao, L. M. Shen, P. Padhan and A. Gupta, J. Am. Chem. Soc., 2007, 129, 12408.

19 K. Ramasamy, D. Mazumdar, Z. Y. Zhou, Y.-H. A. Wang and A. Gupta, J. Am. Chem. Soc., 2011, 133, 20716.

20 Y.-H. A. Wang, X. Y. Zhang, N. Z. Bao, B. P. Lin and A. Gupta, J. Am. Chem. Soc., 2011, 133, 11072.

21 K. Ramasamy, H. Sims, W. H. Butler and A. Gupta, J. Am. Chem. Soc., 2014, 136, 1587.

22 N. Z. Bao, X. M. Qiu, Y.-H. A. Wang, Z. Y. Zhou, X. H. Lu, C. A. Grimes and A. Gupta, Chem. Commun., 2011, 47, 9441. 23 P. Chao, L. Gao, A. Chaturvedi, N. Z. Bao, K. Yanagisawa, L. M. Shen and A. Gupta, J. Mater. Chem. C, 2015, 3, 12077. 24 Y. J. Kang, J. B. Pyo, X. C. Ye, R. E. Diaz, T. R. Gordon, E. A. Stach and C. B. Murray, ACS Nano, 2012, 7, 645.

25 N. Z. Bao, L. M. Shen, W. An, P. Padhan, C. H. Turner and A. Gupta, Chem. Mater., 2009, 21, 3458.

26 J. Park, K. An, Y. Hwang, J.-G. Park, H.-J. Noh, J.-Y. Kim, J.-H. Park, N.-M. Hwang and T. Hyeon, Nat. Mater., 2004, 3, 891.

27 J. S. Steckel, B. K. H. Yen, D. C. Oertel and M. G. Bawendi, J. Am. Chem. Soc., 2006, 128, 13032. 
28 Y. J. Xiong, J. M. McLellan, J. Y. Chen, Y. D. Yin, Z.-Y. Li and Y. N. Xia, J. Am. Chem. Soc., 2005, 127, 17118.

29 T. Ghodselahi, M. A. Vesaghi, A. Shafiekhani, A. Baghizadeh and M. Lameii, Appl. Surf. Sci., 2008, 255, 2730.

30 E. Malicka, A. Waskowska, J. Heimann, R. Sitko and D. Kaczorowski, J. Alloys Compd., 2012, 513, 353.

31 V. Tsurkan, S. Plogmann, M. Demeter, D. Hartmann and M. Neumann, Eur. Phys. J. B, 2000, 15, 401.

32 B. Canava, J. Vigneron, A. Etcheberry, J. F. Guillemoles and D. Lincot, Appl. Surf. Sci., 2002, 202, 8.
33 C. B. Murray, S. H. Sun, H. Doyle and T. Betley, MRS Bull., 2001, 26, 985.

34 H. L. Sun, H. T. Shi, F. Zhao, L. M. Qi and S. Gao, Chem. Commun., 2005, 34, 4339.

35 D. Farrell, Y. H. Cheng, R. W. McCallum, M. Sachan and S. A. Majetich, J. Phys. Chem. B, 2005, 109, 13409.

36 E. C. Stoner and E. P. Wohlfarth, Philos. Trans. R. Soc., A, 1948, 240, 599.

37 L. Zhang, W. Tong, J. Y. Fan, C. J. Zhang, R. W. Li and Y. H. Zhang, Eur. Phys. J. B, 2011, 83, 325. 